\title{
Surgical Treatment of Chronic Subdural Hematoma: Systematic Review and Meta-Analysis of the Literature
}

\section{Tratamento cirúrgico do hematoma subdural crônico: revisão sistemática e metanálise da literatura}

\author{
Alisson R. Teles ${ }^{1}$ Asdrubal Falavigna ${ }^{1}$ Jorge Kraemer $^{2}$ \\ ${ }^{1}$ Department of Neurosurgery, Laboratory of Clinical Studies and \\ Address for correspondence Alisson R. Teles, MD, Laboratory of \\ Basic Models of Spinal Disorders, Universidade de Caxias do Sul, \\ Caxias do Sul, RS, Brazil \\ ${ }^{2}$ Neurosurgery Unit, Hospital São José - Santa Casa de Porto Alegre, \\ Porto Alegre, RS, Brazil \\ Clinical Studies and Basic Models of Spinal Disorders, Universidade de \\ Caxias do Sul, Caxias do Sul, RS, Brazil \\ (e-mail: alisson.r.teles@gmail.com).
}

Arq Bras Neurocir 2016;35:118-127.

\begin{abstract}
Keywords

- chronic subdural hematoma

- treatment

- surgery

- recurrence

- meta-analysis
\end{abstract}

Background There are many controversies in the literature on the treatment of chronic subdural hematoma (CSDH).

Objective To assess the effects of different surgical techniques and postoperative care on recurrence of CSDH.

Methods Systematic review through Medline search of articles published between January 1990 and July 2011. Controlled observational and randomized clinical trials (RCT) regarding surgical approach, irrigation, drainage, and postoperative patient position in patients with CSDH were included. The outcome was recurrence requiring reoperation. Independent extraction of articles was conducted by 2 authors using predefined data fields, including study risk of bias indicators.

Results 35 publications met inclusion criteria. Pooled analyses did not demonstrate difference in recurrence rates when compared burr-hole craniostomy $(\mathrm{BHC}) \mathrm{x}$ twist-drill craniostomy (TDC) (OR: 0.99; Cl95\%: 0.53-1.84; $p=0.97$ ), BHC x craniotomy (OR: 1.23; CI95\%: 0.78-1.95; $p=0.36$ ), nor TDC x craniotomy (OR: 16.11; CI95\%: 0.85-306.88; $p=0.06)$. In patients receiving $B H C$, pooled analysis showed a lower recurrence rate in patients receiving $2 \mathrm{BHC}$ compared with $1 \mathrm{BHC}$ (OR: 0.58; CI95\%: $0.37-0.88 ; p=0.01)$. The use of drainage system after evacuation of CSDH by BHC reduces the recurrence (OR: $0.41 ; \mathrm{Cl} 95 \%: 0.23-0.74 ; p=0.003)$. There is not enough evidence to support either a specific location of the tip of drain, nor the postoperative patient position as factors influencing on recurrence.

Conclusion Well-designed studies are urgently needed to verify the effectiveness of most neurosurgical procedures routinely performed for CSDH. received

September 24, 2015

accepted

December 1, 2015

published online

February 12, 2016
DOI http://dx.doi.org/

$10.1055 / \mathrm{s}-0035-1571270$. ISSN 0103-5355.
Copyright $\odot 2016$ by Thieme Publicações License terms

Ltda, Rio de Janeiro, Brazil $\circledast(1) \Theta \circledast$ 


\section{Resumo}

Introdução Existem inúmeras controvérsias na literatura sobre o tratamento do hematoma subdural crônico (HSDC).

Objetivo Avaliar os resultados das diferentes técnicas cirúrgicas e cuidados pósoperatórios na recidiva do HSDC.

Métodos Revisão sistemática de artigos publicados no Medline entre Janeiro de 1990 a Julho de 2011. Foram incluídos estudos observacionais controlados e ensaios clínicos randomizados $(E C R)$ relacionados à abordagem cirúrgica, irrigação, uso de dreno e posicionamento no pós-operatório de pacientes com HSDC. O desfecho estudado foi recidivo necessitando reoperação. A extração dos dados foi conduzida de maneira independente por dois autores utilizando campos pré-definidos, incluíndo indicadores de viés dos estudos.

Resultados Trinta e cinco artigos foram incluídos na análise. A metanálise não demonstrou diferença nas taxas de recorrência quando comparadas às técnicas de trepanação burr-hole (BHC) X twist-drill (TDC) (OR: 0,99; IC95\%: 0,53-1,84; $\mathrm{p}=0,97)$, BHC X craniotomia (OR: 1,23; IC95\%: 0,78-1,95; $\mathrm{p}=0,36$ ), nem TDC X craniotomia (OR: 16,11; IC95\%: 0,85-306,88; $\mathrm{p}=0.06$ ). Em pacientes operados por BHC, a metanálise demonstrou menor taxa de recidiva em pacientes operados com $2 \mathrm{BHC}$ em comparação a $1 \mathrm{BHC}(\mathrm{OR}: 0,58$; IC95\%: 0,37-0,88; $\mathrm{p}=0,01)$. O uso de dreno no pós-operatório por $\mathrm{BHC}$ reduziu a recidiva (OR: 0,41; IC95\%: 0,23-0,74; $\mathrm{p}=0,003$ ). Não há evidência suficiente que aponta do dreno ou a posição do paciente no pósoperatório tenham influência na chance de recidiva.

Conclusão Estudos bem delineados são necessários para comparar a efetividade da maioria dos procedimentos neurocirúrgicos realizados rotineiramente para HSDC.

\section{Introduction}

Chronic subdural hematoma (CSDH) is one of the most common conditions in neurosurgery. Its incidence is estimated to be $1.72 / 100,000 /$ year in general and $7.35 / 100,000 /$ year in the age group from 70 to 79 years. ${ }^{1}$ With a greater proportion of elderly people over the next decades, the incidence of this pathology will further increase. Despite its relative frequency, a range of surgical techniques are currently used and low importance in the literature has been given to ascertain about the effectiveness of these practices.

Three previous meta-analyses were published regarding management of $\mathrm{CSDH}^{2-4}$ However, two important pitfalls arise from these publications. First, due to the variation of risk of bias across studies, it is generally accepted that criteria should be set to limit the kinds of evidence included in a systematic review. ${ }^{5}$ Despite the disagreement about the study design criteria that should be included in absence of well designed randomized clinical trials (RCT), it is generally accepted that the strategy should be to include only the best available study designs. In this sense, all previous authors included uncontrolled studies in their analyses, such as case series together with controlled studies, which carry great risk of bias. Different designs are susceptible to different biases, and it is often unclear which biases have the greatest impact and how they vary between clinical situations. ${ }^{5}$ Second, the statistical methods used to account for treat- ment effects and risk of bias among studies are in disagreement with the recent guidelines for reporting metaanalyses. ${ }^{6}$

Treatment of CSDH varies among neurosurgical centers, ${ }^{7,8}$ and there is no consensus in the literature about the impact of these techniques on patient outcome. The objective of this review was to assess the effects of different surgical techniques described in the literature on recurrence of CSDH.

\section{Methodology}

\section{Electronic Literature Database}

We undertook a systematic literature review by conducting a Medline/Cochrane search of articles published between January 1990 and July 2011 using the medical subheading "chronic subdural hematoma" in combination with any of the following words: "treatment," "surgery," "evacuation," "management," "drainage," and "recurrence." We limited our results to humans, articles published in English language, and with available abstracts. Reference lists of key articles were also systematically checked.

We identified all articles regarding surgical approach, irrigation, drainage, and postoperative patient position. Observational studies with control groups and RCT were included in this review. Articles were excluded if: there was no report on recurrence rates or if it was not reported as reoperation; if there were no comparative analyses (e.g., irrigation x no-irrigation, drainage $\mathrm{x}$ no-drainage) or 
if comparison would not be taken without excluding any variable (e.g., drainage use comparing patients who underwent BHC and TDC); if pediatric patients were included without subgroup analyses; if the sample was composed by recurrent hematomas or those associated with ventricular shunt; or if the sample was lower than 30 patients. Others exclusions included narrative reviews, editorials, case-reports and non-English-written articles.

\section{Data Extraction}

Each retrieved citation was independently reviewed by two authors (ART, AF) using predefined data fields. Most articles were excluded on the basis of information provided by the abstract. Citations that seemed to be appropriate or those that could not be excluded unequivocally from the abstract were identified, and the corresponding full-text reports were reviewed by the two authors (ART, AF). Any disagreement between them was resolved by consensus. From the included articles, the following data were extracted: study design, sample size, surgical technique, recurrence rate, level of evidence, and risk of bias of the study. In patients with bilateral CSDH, we considered the number of affected sides in the analyses; if the article did not contemplate this information, we evaluated number of patients.

\section{Risk of Bias Assessment}

Level of evidence (LOE) ratings and risk of bias were assigned to each article independently by two reviewers (ART, AF). Any disagreement was resolved by consensus. We used the criteria set by the Centre for Evidence Based Medicine ${ }^{9}$ to assess the level of evidence from each article. Risk of bias was evaluated with The Cochrane Risk of Bias Tool ${ }^{10}$ for RCT and The Newcastle-Ottawa Scale ${ }^{11}$ for observational studies. The Cochrane Risk of Bias Tool assesses five domains of bias: selection bias (random sequence generation and allocation concealment), performance bias (blinding of participants and personnel), detection bias (blinding of outcome assessment), attrition bias (incomplete outcome data) and reporting bias (selective reporting). The category other bias is included to ascertain bias due to problems not covered elsewhere. $^{12}$ The Newcastle-Ottawa consists of three parameters of risk of bias assessment: selection, comparability, and outcome. This scale assigns a maximum of 4 points for selection, a maximum of 2 points of comparability, and a maximum of 3 points for outcome. The higher the score, the lower the risk of bias of the study. We presented the results of the risk of bias assessment and level of evidence separately for each article.

\section{Analysis}

The definition of CSDH relied on the original authors' assessment of the radiographic characteristics of the subdural collection in classifying it as chronic rather than acute or subacute. Only adult patients were included in the analysis. Recurrence was primarily defined as reoperation of the hematoma. Articles that considered recurrence as reformation of subdural collection but did not report on reoperation rates were excluded from the analysis. Regarding surgical approach, cranial openings higher than $3 \mathrm{~cm}$ were classified as craniotomy, lower than $0.5 \mathrm{~cm}$ as twist-drill craniostomy, and those in between as burr-hole craniostomy. ${ }^{4}$

We extracted recurrence rates regarding different techniques (e.g., irrigation x no-irrigation, drainage x no-drainage) from each article. Comparisons between surgical approach, number of burr-holes, drain usage, irrigation and postoperative patient position were analyzed. Statistical analyses were conducted with RevMan software version 5.1. Due to the paucity of high quality randomized clinical trials on treatment options for CSDH, meta-analyses were conducted with both observational and RCT using fixed effects models. We calculated odds ratios (OR) and corresponding confidence intervals $(\mathrm{CI})$ for recurrence in all treatment comparisons. Heterogeneity between studies was tested using Chi-square test and the I2 statistic (inconsistency). ${ }^{13}$ The last represents the percentage of total variation across studies that is due to heterogeneity rather than chance. Inconsistency of $25 \%$ is considered low, $50 \%$ moderate, and more than $75 \%$ high. $^{13}$

\section{Results}

We identified a total of 633 articles after the Medline search (-Fig. 1). Of these papers, 108 underwent full-text review. After full-text review, we excluded 73 articles for the following reasons: no comparative groups or no comparisons could be done with provided data $(n=47)$; no report on recurrence rates or it was not reported as reoperation $(n=22)$; only recurrent hematomas included $(n=1)$; report on pharmacological treatment $(n=2)$; and sample size lower than 30 patients $(n=1)$ ( - Fig. 1$)$. After exclusions, 35 original articles were analyzed by the authors. Most of the included articles were retrospective $(N=24 ; 68.6 \%)$. There were three prospective studies (8.6\%) and 8 randomized clinical trials (22.8\%). Risk of bias for observational and RCTs are presented in - Tables 1 and 2, respectively. It is possible to observe high risk of bias in most of the RCTs and observational studies. For example, the majority were small and underpowered RCTs

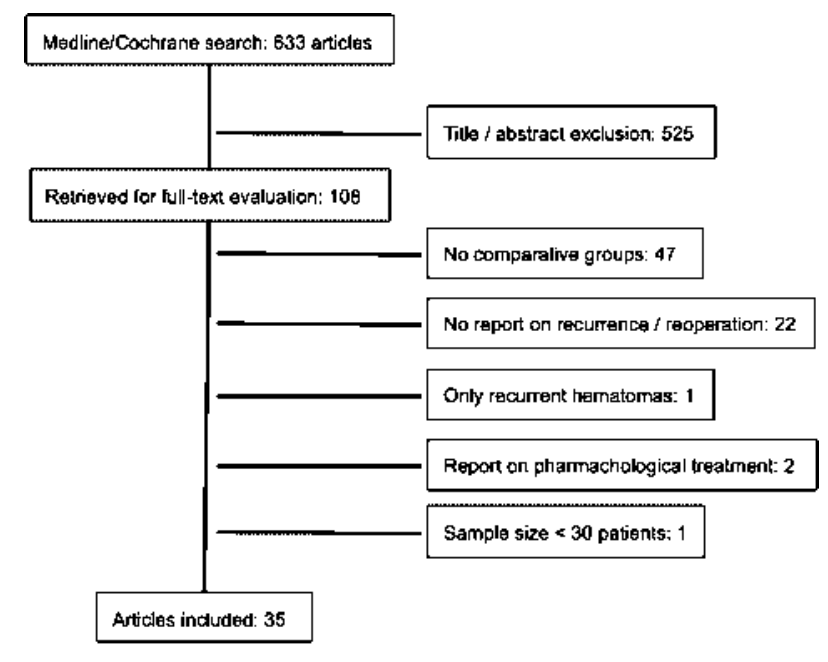

Fig. 1 Literature search and studies' selection. 
Table 1 Risk of bias assessment for observational studies

\begin{tabular}{|c|c|c|c|c|}
\hline \multirow[t]{2}{*}{ Study } & \multicolumn{3}{|c|}{ Newcastle-Ottawa Scale } & \multirow[t]{2}{*}{ LOE } \\
\hline & Selection & Comparability & Outcome & \\
\hline Wakai et $\mathrm{al}^{34}$ & 3 & 1 & 2 & $2 b$ \\
\hline Sambasivan $^{19}$ & 3 & 0 & 3 & $2 c$ \\
\hline Smely et $\mathrm{al}^{23}$ & 3 & 1 & 3 & $2 b$ \\
\hline Ernestus et al ${ }^{14}$ & 3 & 0 & 2 & 4 \\
\hline Suzuki et $\mathrm{al}^{31}$ & 3 & 0 & 2 & $2 b$ \\
\hline Nakaguchi et al $^{42}$ & 3 & 0 & 2 & $2 b$ \\
\hline Tanikawa et al ${ }^{20}$ & 3 & 0 & 2 & 4 \\
\hline Oishi et $\mathrm{al}^{30}$ & 2 & 0 & 3 & 4 \\
\hline Williams et $\mathrm{al}^{22}$ & 3 & 0 & 1 & 4 \\
\hline Kuroki et al ${ }^{29}$ & 4 & 0 & 2 & $2 b$ \\
\hline Yamamoto et al ${ }^{41}$ & 4 & 2 & 2 & $2 c$ \\
\hline Lind et $\mathrm{al}^{38}$ & 4 & 0 & 1 & $2 b$ \\
\hline Lee et $\mathrm{al}^{15}$ & 4 & 0 & 2 & 4 \\
\hline Baechli et al ${ }^{25}$ & 4 & 0 & 1 & $2 c$ \\
\hline Kiymaz et $\mathrm{al}^{37}$ & 3 & 0 & 2 & 4 \\
\hline Taussy et $a^{28}$ & 3 & 2 & 2 & $2 b$ \\
\hline Zakaraia et al $^{52}$ & 4 & 0 & 2 & $2 c$ \\
\hline Torihashi et al ${ }^{32}$ & 4 & 2 & 2 & $2 c$ \\
\hline Yu et $\mathrm{al}^{40}$ & 4 & 0 & 2 & $2 c$ \\
\hline Lee et $\mathrm{al}^{16}$ & 4 & 0 & 2 & $2 b$ \\
\hline Han et al ${ }^{26}$ & 3 & 2 & 2 & $2 b$ \\
\hline Baé et $\mathrm{al}^{43}$ & 4 & 2 & 2 & $2 c$ \\
\hline Rughani et al ${ }^{18}$ & 4 & 2 & 2 & $2 b$ \\
\hline Kansal et $\mathrm{al}^{27}$ & 3 & 0 & 3 & $2 \mathrm{~b}$ \\
\hline Kurabe et al ${ }^{47}$ & 3 & 1 & 3 & $2 \mathrm{~b}$ \\
\hline White et $\mathrm{al}^{21}$ & 2 & 0 & 1 & 4 \\
\hline Miranda et al ${ }^{17}$ & 3 & 0 & 2 & $2 c$ \\
\hline
\end{tabular}

Abbreviation: LOE, level of evidence.

Table 2 Risk of bias assessment for randomized clinical trials

\begin{tabular}{|c|c|c|c|c|c|c|c|c|}
\hline Study & $\begin{array}{l}\text { Random } \\
\text { sequence } \\
\text { generation }\end{array}$ & $\begin{array}{l}\text { Allocation } \\
\text { concealment }\end{array}$ & $\begin{array}{l}\text { Blinding of } \\
\text { participants } \\
\text { and personnel }\end{array}$ & $\begin{array}{l}\text { Blinding of } \\
\text { outcome } \\
\text { assessment }\end{array}$ & $\begin{array}{l}\text { Incomplete } \\
\text { outcome data }\end{array}$ & $\begin{array}{l}\text { Selective } \\
\text { reporting }\end{array}$ & $\begin{array}{l}\text { Other } \\
\text { bias }\end{array}$ & LOE \\
\hline Tsutsumi et al ${ }^{33}$ & Low & Unclear & Low & Unclear & Low & High & High & $2 b$ \\
\hline Nakajima et al ${ }^{46}$ & Unclear & Unclear & Low & Unclear & Low & Low & High & $2 b$ \\
\hline Muzii et $\mathrm{al}^{24}$ & High & High & Low & Unclear & Low & High & Unclear & $2 b$ \\
\hline Erol et $\mathrm{al}^{35}$ & Unclear & Unclear & Low & Unclear & Low & High & Unclear & $2 b$ \\
\hline Abouzari et al ${ }^{44}$ & High & High & Low & High & Low & High & High & $2 b$ \\
\hline Ishfaq et al ${ }^{45}$ & Low & High & Low & Unclear & Low & Low & High & $2 b$ \\
\hline Santarius et $\mathrm{al}^{39}$ & Low & Low & Low & Low & Low & Low & Low & $1 b$ \\
\hline Javadi et al ${ }^{36}$ & Unclear & Unclear & Low & Unclear & Low & Low & High & $2 b$ \\
\hline
\end{tabular}

Abbreviation: LOE, level of evidence. 


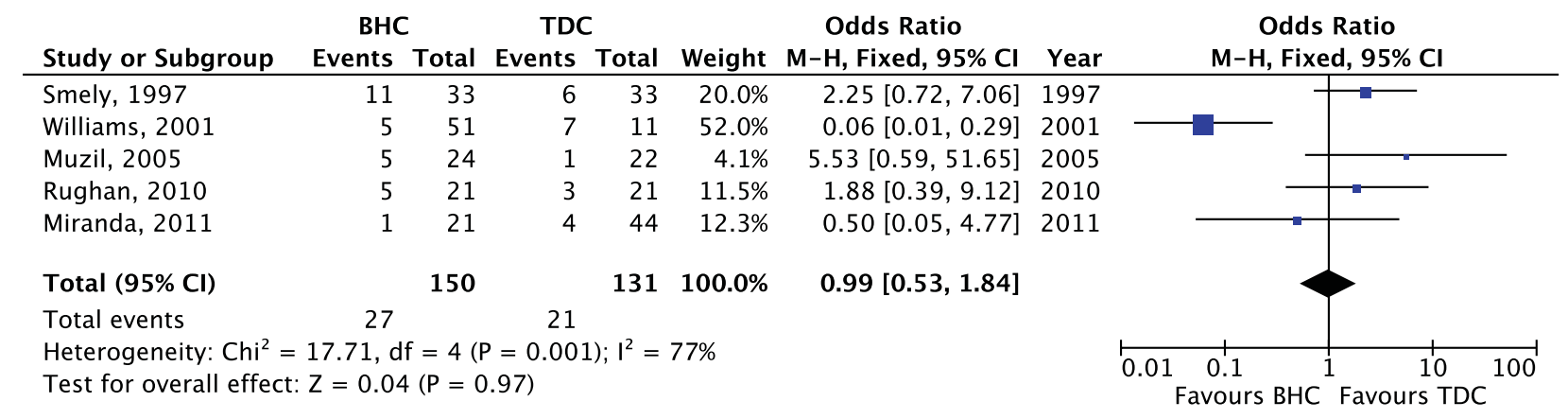

Fig. 2 Forest-plot of comparisons between burr-hole craniostomy versus twist-drill craniostomy.

and most of them did not describe methods of randomization and assessment of outcome. For observational studies, few reported analyses for confounding factors and a great part did not described adequate follow-up period. The majority of papers provided level of evidence $2 \mathrm{~b}(N=19 ; 54.2 \%)$, followed by level 2c $(N=8 ; 22.9 \%), 4(N=7 ; 20.0 \%)$, and $1 \mathrm{~b}$ $(N=1 ; 2.9 \%)$.

\section{Surgical Approach}

Nine retrospective, ${ }^{14-22}$ one prospective ${ }^{23}$ and one $\mathrm{RCT}^{24}$ were included. All of these studies performed comparative analyses of two or more surgical approaches for CSDH and reported recurrence as reoperation rates. Concerning patients who received BHC, four studies reported use of two burr-holes, ${ }^{15,17,19,20}$ three studies used single burrhole, ${ }^{14,22,23}$ three papers did not specify the number of burr-holes performed in each patient, ${ }^{18,21,24}$ and Lee et al $^{16}$ reported one burr-hole in 25 patients and two burrholes in 32 patients. Nine studies reported postoperative drainage use $\mathrm{e}^{14-20,23,24}$ and two did not use drain. ${ }^{21,22}$ Sambasivan ${ }^{19}$ described craniotomy with subtemporalis marsupialization in patients who underwent craniotomy.

Regarding comparisons of recurrence rates in patients treated with BHC versus TDC, the pooled analysis of five articles $^{17,18,22-24}$ did not demonstrate statistically significant difference between the two groups ( - Fig. 2; OR: 0.99; CI95\%: $0.53 ; p=0.97$ ). This model proved to have significant heterogeneity (Chi-square: $17.71 ; p=0.001, \mathrm{I} 2: 72 \%$ ). If Williams' study ${ }^{22}$ would be removed from the analysis, 12 would be $0 \%$ (Chi-square: $2.29 ; p=0.51$ ) and there still would be no statistically significant difference between the two surgical approaches for CSDH (OR: 1.99; CI95\%: 0.94$4.25 ; p=0.07$ )

We retrospectively reviewed comparisons of BHC versus craniotomy in seven publications. ${ }^{14-17,19-21}$ In general, option to perform each technique was based on study period or preference of attending neurosurgeon. No article reported on other preoperative variable that could interfere in decision of surgical approach. A pooled analysis with all papers proved to have significant heterogeneity (chi-square: 67.69; $p<0.00001$; 12: 91\%), mainly caused by Sambasivaǹs study. ${ }^{19}$ We opted to exclude that study from the analysis to reduce heterogeneity from the pooled analysis (chisquare: $6.88 ; p=0.23 ; \mathrm{I} 2: 27 \%$ ). The meta-analysis demonstrates that recurrence do not differ between patients receiving BHC or craniotomy for CSDH (- Fig. 3; OR: 1.23; CI95\%: 0.78-1.95; $p=0.36$ ).

Only one paper ${ }^{17}$ reported comparisons of recurrence in patients who received TDC versus craniotomy for CSDH. We observed that 4 of 44 patients treated with TDH and none of 70 patients treated with craniotomy needed reoperation (OR: 16.11; CI95\%: 0.85-306.88; $p=0.06$ ).

\section{Number of Burr-Holes}

Five retrospective studies ${ }^{16,25-28}$ evaluated the influence of number of burr-holes on recurrence of CSDH. Four studies performed irrigation associated with postoperative drainage system, ${ }^{16,25,26,28}$ and one did not use drain. ${ }^{27}$ Despite the

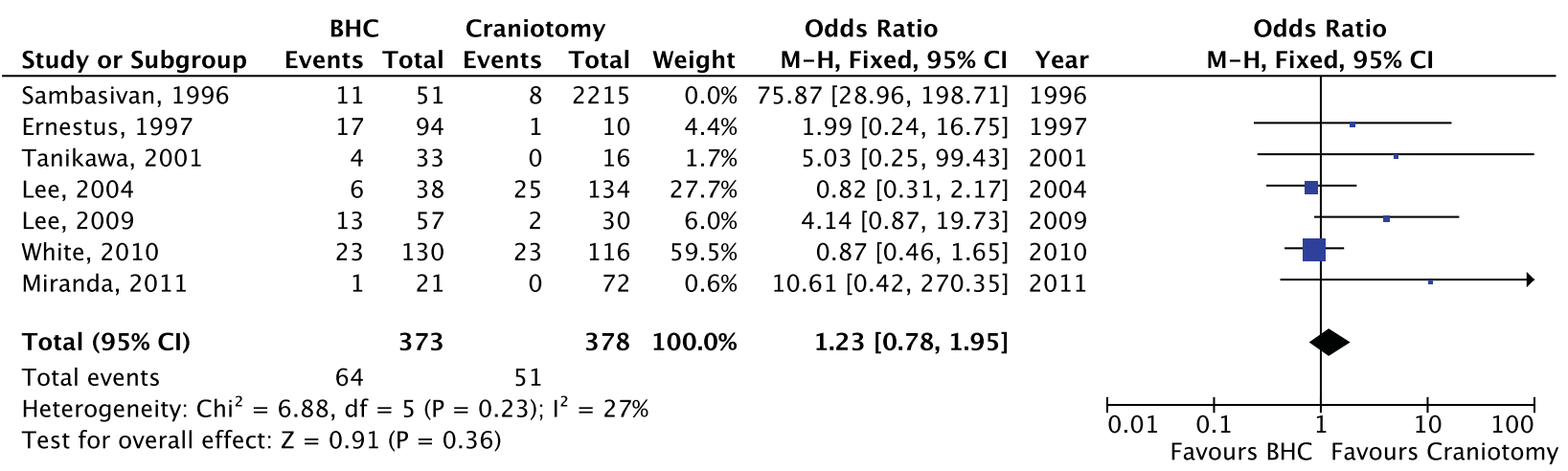

Fig. 3 Forest-plot of comparins between burr-hole craniostomy versus craniotomy. 


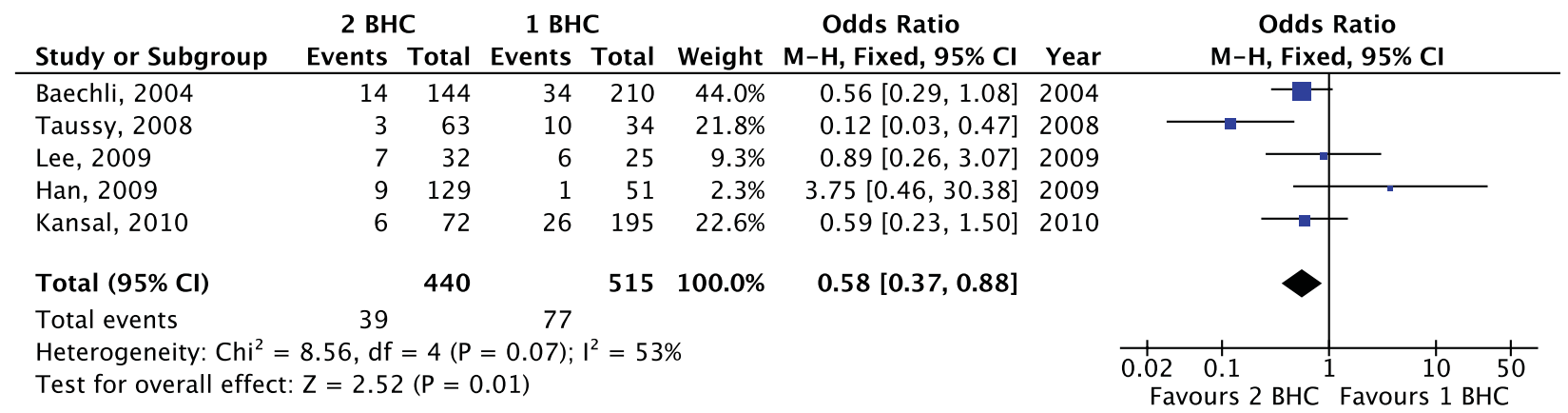

Fig. 4 Forest-plot of comparisons between one versus two burr-holes.

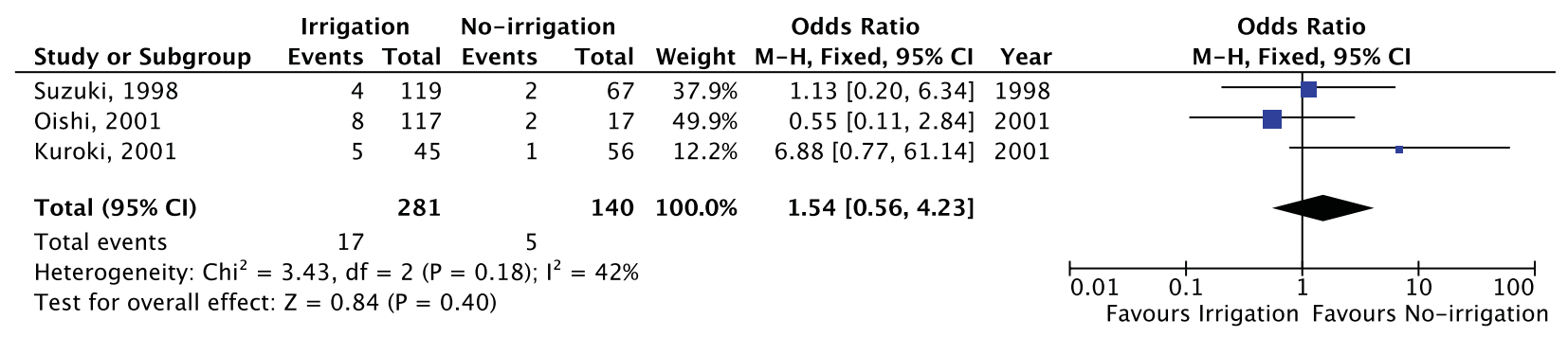

Fig. 5 Forest-plot of comparisons between intraoperative irrigation versus non-irrigation of subdural cavity.

Chi-square not having demonstrated statistically significant heterogeneity among studies $(p=0.07)$, inconsistency proved to be moderate (I2: 53\%). At least two reasons could explain this percentage: the different surgical technique used in the study by Kansal et $\mathrm{al}^{27}$ (without drain) and the absence of criteria/randomization to perform 1 or 2 BHC among the studies. The meta-analyses of such data demonstrated that $2 \mathrm{BHC}$ is associated with lower recurrence rates compared with 1 BHC (-Fig. 4; OR: 0.58; CI95\%: 0.37-0.88).

\section{Intraoperative Irrigation}

Three retrospective studies ${ }^{29-31}$ evaluated the recurrence rates between patients who underwent or did not intraoperative irrigation using BHC and postoperative drainage system. Kuroki et $\mathrm{al}^{29}$ verified recurrence in $11.1 \%$ in irrigation group and $1.8 \%$ in no-irrigation group ( $p=0.049$; OR $=6.875$, CI95\%: 0.773-61.143). The other two papers ${ }^{30,31}$ did not find this difference on the basis of irrigation. The analysis of all reported cases did not find difference between the two treatment groups concerning recurrence rates
(-Fig. 5). Inconsistency among studies proved to be moderate (I2: $42 \%$; Chi2: $3.43, p=0.18$ ).

\section{Drainage}

Nine studies ${ }^{22,32-39}$ provided information about recurrence regarding drainage usage after $\mathrm{BHC}$ and irrigation for $\mathrm{CSDH}$. There were four RCTs, ${ }^{33,35,36,39}$ four retrospective $22,32,37,38$ and one ${ }^{34}$ prospective observational studies. Only one RCT was classified as providing level $1 \mathrm{~b}$ of evidence. ${ }^{39}$ We conducted meta-analysis with all RCT, excluding observational studies. Tsutsumi et $\mathrm{al}^{33}$ describe, in the same article, data regarding a retrospective chart review (four-year period) and a RCT comparing 1 BHC with and without drainage system; only data regarding the RCT were included in the metaanalysis.

In relation to observational studies, ${ }^{22,32,34,37,38} 3$ papers $^{34,37,38}$ reported lower recurrence rates in patients who received drain compared with patients without drain. The remaining two 22,32 did not find difference in recurrence concerning the use of drain.

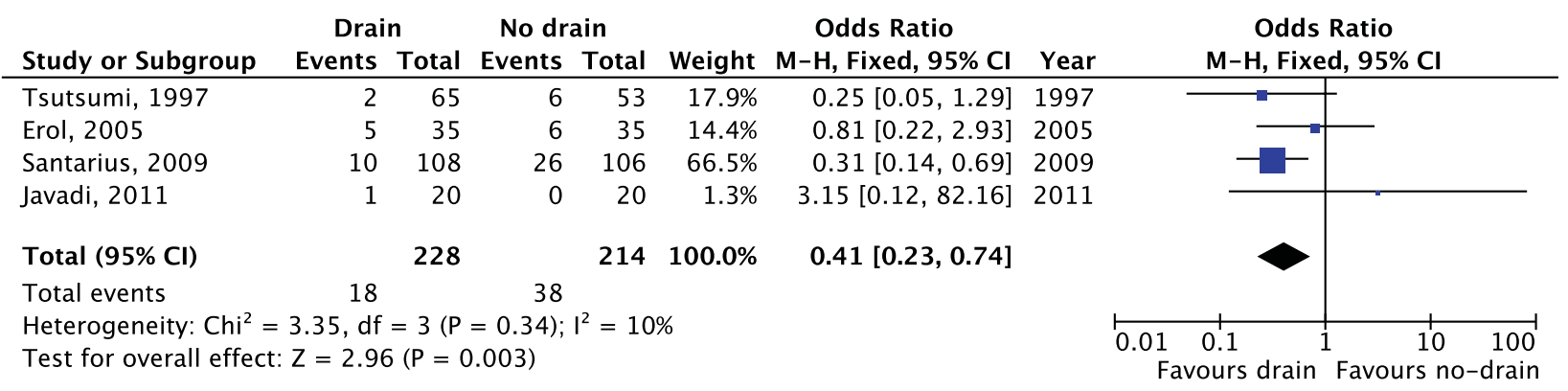

Fig. 6 Forest-plot of comparisons between use of drain versus no-drain after burr-hole craniostomy. 
Santarius et $\mathrm{al}^{39}$ performed a RCT to verify the effect of postoperative drainage after burr-hole evacuation of CSDH. They randomized 108 patients to drain group and 107 to nodrain group. The incidence of recurrence of hematoma was higher in the no-drain group ( $9 \% \times 24 \% ; p=0.0031)$. In addition, the mortality at 6 -months was higher in no-drain group ( $9 \% \times 18 \% ; p=0.0424$ ). The meta-analysis of all RCT demonstrated that the use of drain reduces the risk of recurrence after BHC for CSDH (-Fig. 6; $p=0.003$; OR: 0.41; CI95\%: $0.23-0.74$ ). The I2 value was $10 \%$, demonstrating that only $10 \%$ of variation of recurrence rates can be explained by heterogeneity among the studies.

\section{Duration of Drainage}

Only one retrospective study ${ }^{40}$ evaluated the duration of drainage and its relation with recurrence of CSDH. Yu et al ${ }^{40}$ performed $1 \mathrm{BHC}$ with irrigation and drainage in $100 \mathrm{pa}-$ tients. The criteria for removing the drainage system were brain re-expansion on computed tomography (CT) scans or when drainage ceased. Analyses were conducted based on recurrence rates of 3 groups according to duration of drainage: $<72$ hours, $16.3 \%$ of recurrence; $72-119$ hours, $2 \%$ of recurrence; and $\geq 120$ hours, no recurrence. Bivariate analyses demonstrated a statistically significant difference in the groups ( $p=0.007$ ), that is, the risk of recurrence was higher when the drainage system was removed earlier. However, caution should be taken when interpreting these results due to its high risk of bias. First, as it was a retrospective study, all biases of a non-randomized study are present. Also, the sample size in each group is considered small for such lower incidence of recurrence found in the study.

\section{Position of Drain}

Three papers ${ }^{41-43}$ were included in the review concerning the influence of position of the tip of drain in recurrence after surgery for CSDH, one $\mathrm{RCT}^{42}$ and two retrospective studies. ${ }^{41,43} \mathrm{~A}$ meta-analysis could not be performed due to discrepancy of the groups among studies.

Nakaguchi et $\mathrm{al}^{42}$ designed a RCT to compare recurrence in patients with different locations of the tip of the drain after evacuation of CSDH by BHC and irrigation. In the period of study, 135 patients with CSDH were treated in their institution, but in only 63 patients the tip of catheter was randomly decided and then precisely determined using CT on the day after surgery. The patients were randomized to receive a drain in frontal or occipital region. However, as mentioned by the authors, each catheter was blindly inserted into the subdural space at surgery and it was unclear where the tip was placed. Therefore the catheter position was checked by a postoperative CT. The data were analyzed regarding the location of drain according to that CT. Patients with drains in the frontal region had lower recurrence rates $(1 / 21 ; 5 \%)$, in comparison with parietal $(3 / 8 ; 38 \%)$, occipital $(5 / 25 ; 20 \%)$, and temporal base $(3 / 9 ; 33 \%)$ regions $(p=0.04)$. This study has some biases that should be considered. First, the lack of details on the non-randomization and noninclusion of a large amount of patients treated in the study period in that institution could represent a selection bias. Also, the authors did not provide information considering an intention to treat analysis, no details on randomization were provided, and the study is underpowered due to the small sample size.

Yamamoto et $\mathrm{al}^{41}$ underwent a retrospective chart review of 105 consecutive patients with CSDH who underwent surgery. Multivariate analyses on risk factors for recurrence of CSDH demonstrated that the position of drain was not related to recurrence in the analysis (10/94 frontal $\times 1 / 11$ other; $p=0.874)$. Baé et $\mathrm{a}^{43}$ retrospectively reviewed 312 patients treated with TDC and drainage system. Recurrence rates were not different whether the drain was located in the frontal region $(24 \%)$ or the parietal region (21\%). In both of these two retrospective studies, the authors did not provide information on the selection of drainage location nor on determination of drain location postoperatively.

\section{Patient Postoperative Position}

Three RCTs were included in the analysis. ${ }^{44-46}$ Abouzari et $\mathrm{al}^{44}$ conducted a RCT with 84 patients to compare flat head position versus elevated head position in the postoperative period of BHC, irrigation, and drainage for CSDH. They report that the percentage of patients with reformation of subdural collection was higher in patients who underwent elevated head position compared with flat head position (19\%\% $\times 2.3 \% ; p=0.02)$. However, reoperation was performed in only one patient who underwent flat head position in the postoperative period. As our meta-analysis considered recurrence as reformation of a symptomatic CSDH requiring reoperation, only that patient was classified as having recurrence in our final analysis. Data provided in - Fig. 7 demonstrate that there is no statistically significant difference between two postoperative patient positions regarding recurrence after BHC for CSDH.

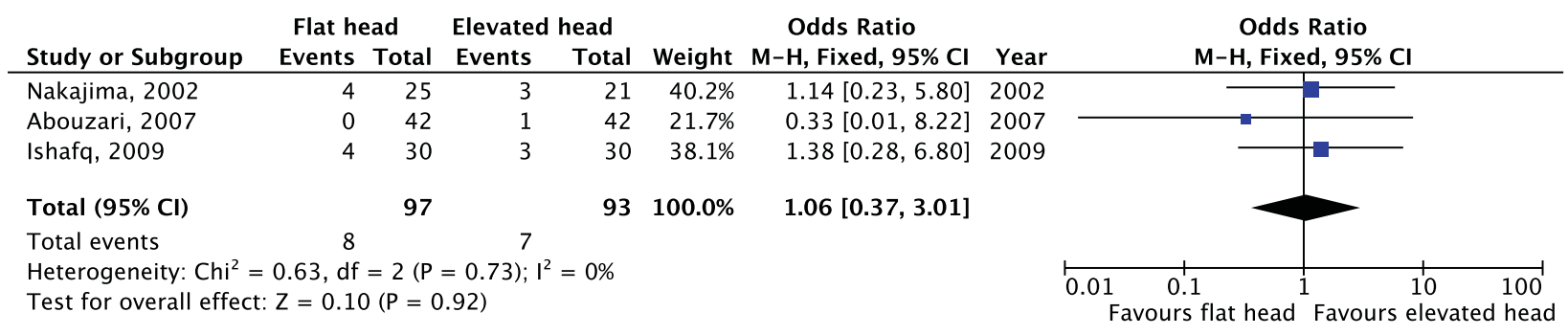

Fig. 7 Forest-plot of comparisons between flat and elevated head in postoperative period. 


\section{Timing to Patient Mobilization}

One $^{47}$ retrospective study provided information regarding duration of bed rest and recurrence after evacuation of CSDH. Kurabe et $\mathrm{al}^{47}$ assessed timing of bed rest in patients older than 65 to verify if early mobilization in these patients would affect recurrence rates and postoperative complications. The authors performed BHC with irrigation and closed drainage system in 182 patients. Half of them were maintained in supine position for at least two days after the operation (delayed mobilization group), while 91 patients had the drainage system removed and were able to walk the day after the operation (early mobilization group). Recurrence was observed in 6 patients of delayed mobilization group and in 8 patients of early mobilization group $(6.6 \% \times 8.8 \%$, respectively; $p=0.58$ ). The incidence of patients who suffered from at least one complication was higher in the delayed mobilization group compared with early mobilization group ( $26.4 \% \times 12.1 \%$, respectively; $p=0.015)$. The results of this retrospective study demonstrate that early mobilization in elderly patients may have benefits in reducing postoperative complications without increasing recurrence rates after evacuation of CSDH. A RCT is encouraged to prove these findings.

\section{Discussion}

Despite the epidemiological importance of CSDH, high quality studies on the treatment of this condition are scarce in the neurosurgical literature. In our review, only 8 RCTs were found and most of them presented high risk of bias. The majority of the analyses were performed using comparative analyses of observational studies. Nonetheless, the strengths of our review include the comprehensive and reliable search, data extraction, and appropriate and widely acceptable methodology of meta-analysis and risk of bias assessment. Strict identification of patients who underwent reoperation aside from radiographic reformation of subdural collection is also an important factor of this review. Re-expansion of brain tissue in elderly patients is sometimes delayed due to absence of cerebral complacency and some subdural collection is found in postoperative exams in most cases of patients not requiring reoperation.

Results from our meta-analyses demonstrate the absence of evidence to support superiority of any surgical technique (BHC x TDC x craniotomy) in reducing recurrence rates after evacuation of CSDH. These results are in disagreement with the other systematic reviews already published. ${ }^{2-4}$ In the analyses of Weigel et $\mathrm{al}^{4} \mathrm{BHC}$ and craniotomy were associated with lower recurrence rates. Lega et $\mathrm{al}^{3}$ used Monte Carlo simulation model and concluded that BHC balances a low recurrence rate with a low incidence of highly morbid complications. However, those papers included uncontrolled studies in their review. This kind of publication has a high risk of confirmation bias, the tendency of publishing positive results. Also, for systematic reviews without existing well designed RCTs, the inclusion criteria should consider only the best available study designs, because different designs are susceptible to different biases, and it is often unclear which biases have the greatest impact and how they vary between clinical situations. ${ }^{5}$ Our review included the best of existing evidence in the literature regarding management of this disease. Due to the paucity of well designed RCTs, we included observational controlled studies.

$\mathrm{BHC}$ is the most common surgical technique to evacuate CSDH in neurosurgical centers. ${ }^{7,8,48}$ Our pooled analyses demonstrated that 2 burr-holes presents best results when compared with only 1 burr-hole. However, this result are based on retrospective studies, ${ }^{16,25-28}$ and majority of them have a high risk of comparability bias; for example, patients were not paired by radiographic features. Also, the Despite of irrigation of subdural cavity being a common practice during evacuation of $\mathrm{CSDH}, 3$ retrospective studies ${ }^{29-31}$ compared results of patients who received or not intraoperative irrigation. The pooled analyses of these data did not demonstrate difference in recurrence rates between these two techniques. The only high quality RCT found assessed the effectiveness of drain use in patients receiving BHC. ${ }^{39}$ Our analysis demonstrates that the use of drain is associated with a low risk of recurrence in such patients.

$\mathrm{CSDH}$ is commonly associated with cerebral atrophy and the associated increase in potential space in the subdural area. This fact results in some practitioners placing the patient's head flat during treatment in an attempt to decrease this potential space. In fact, the majority of studies report the use of a flat head position for preventing hematoma recurrence. On the other hand, there are other theoretical explanations to support the use of elevated head in the management of CSDH. First, as performed in acute subdural hematomas, some authors raise patients' head to reduce intracranial pressure improving the cerebral perfusion pressure $^{48}$; besides, one mechanism thought to explain the growth of $\mathrm{CSDH}$ is an increased oncotic pressure within the encapsulated space secondary to partial clot liquefaction, ${ }^{48}$ therefore raising the patients' head could possibly reduce this pressure gradient. Finally, a secondary hypothesis suggests that expansion of hematoma is caused by recurrent bleeding, ${ }^{49,50}$ and this would be caused by dilated and abnormal vessels contained in the outer membrane of the hematoma, ${ }^{51}$ hence keeping the patients' head elevated could decrease this source of hemorrhage. Another theoretical superiority of elevated head position includes reduction of aspiration and early mobilization of the patient. Our results do not support superiority of any of these patient positions in reducing recurrence of CSDH. After a pooled analysis of three low quality RCT, there was no statistically significant difference in recurrence rates in patients who underwent this position compared with patients who underwent elevated head position. Well-designed RCT are needed to verify the influence of head position in recurrence and complications after drainage of CSDH.

Our review has some limitations that must be pointed. Most of them are relative to the evidence itself, requiring attention for both interpreting the results and conducting future research. Many of the identified studies had a high risk for observational study bias due to the lack of control for confounders and covariates (such as the lack of adjustment 
for age, hematoma volume or radiographic features). For example, confounding by indication of each surgical technique (e.g., $1 \times 2$ BHC; BHC or TDH x craniotomy) could therefore have a greater likelihood that larger hematomas would be treated with craniotomy or 2 BHC besides $1 \mathrm{BHC}$. In adittion, due to the paucity of high quality RCT, and majority of observational studies have high risk of bias when reporting other outcomes such as surgical morbidity and clinical complications, we opted to do not included these outcomes in our meta-analysis.

\section{Conclusions and Implications for Future Research}

There is very low quality evidence for the efficacy of most neurosurgical procedures for CSDH because of high risk of bias of the trials. The pooled analysis of the best existing evidence in the literature does not demonstrate differences in recurrence rates for CSDH treated either by BHC, TDC nor craniotomy. If BHC is performed, the use of a drainage system reduces the risk of recurrence. There is not enough evidence to support a specific location of tip of drain, nor the duration of drainage and its impact on recurrence. Regarding postoperative management, the best existing evidence does not demonstrate difference in recurrence rates in patients kept with flat compared with elevated head position. Also, there is not enough evidence to support that longer duration of bed rest reduces the risk of hematoma recurrence after drainage in elderly patients. Well designed studies are urgently needed.

\section{References}

1 Foelholm R, Waltimo O. Epidemiology of chronic subdural haematoma. Acta Neurochir (Wien) 1975;32(3-4):247-250

2 Ducruet AF, Grobelny BT, Zacharia BE, et al. The surgical management of chronic subdural hematoma. Neurosurg Rev 2012;35(2): 155-169, discussion 169

3 Lega BC, Danish SF, Malhotra NR, Sonnad SS, Stein SC. Choosing the best operation for chronic subdural hematoma: a decision analysis. J Neurosurg 2010;113(3):615-621

4 Weigel R, Schmiedek P, Krauss JK. Outcome of contemporary surgery for chronic subdural haematoma: evidence based review. J Neurol Neurosurg Psychiatry 2003;74(7):937-943

5 Higgins JP, Deeks JJ. Chapter 7: Selecting studies and collecting data. In: Higgins JP, Green S, eds. Cochrane handbook for systematic reviews of interventions Version 5.1.0 (Updated March 2011). www.cochrane-handbook.org2011

6 Liberati A, Altman DG, Tetzlaff J, et al. The PRISMA statement for reporting systematic reviews and meta-analyses of studies that evaluate healthcare interventions: explanation and elaboration. BMJ 2009;339:b2700

7 Cenic A, Bhandari M, Reddy K. Management of chronic subdural hematoma: a national survey and literature review. Can J Neurol Sci 2005;32(4):501-506

8 Santarius T, Lawton R, Kirkpatrick PJ, Hutchinson PJ. The management of primary chronic subdural haematoma: a questionnaire survey of practice in the United Kingdom and the Republic of Ireland. Br J Neurosurg 2008;22(4):529-534

9 Phillips B, Ball C, Sackett D, et al. Oxford Centre for Evidence-based Medicine Levels of Evidence. 2009
10 Higgins JP, Altman DG, Sterne JA. Chapter 8: Assessing risk of bias in included studies. In: Higgins JP, Green S, eds. Cochrane handbook for systematic reviews of interventions Version 5.1.0 (Updated March 2011). www.cochrane-handbook. org2011

11 Wells GA, Shea B, ÒConnell D, et al. The Newcastle-Ottawa Scale (NOS) for assessing the quality of nonrandomised studies in meta-analyses. 2012. http://www.ohri.ca/programs/clinical_epidemiology/oxford.asp. Accessed Accessed on 4 may 2012.

12 Higgins JP, Altman DG, Gøtzsche PC, et al; Cochrane Bias Methods Group; Cochrane Statistical Methods Group. The Cochrane Collaboration's tool for assessing risk of bias in randomised trials. BMJ 2011;343:d5928

13 Higgins JP, Thompson SG, Deeks JJ, Altman DG. Measuring inconsistency in meta-analyses. BMJ 2003;327(7414):557-560

14 Ernestus RI, Beldzinski P, Lanfermann H, Klug N. Chronic subdural hematoma: surgical treatment and outcome in 104 patients. Surg Neurol 1997;48(3):220-225

15 Lee JY, Ebel H, Ernestus RI, Klug N. Various surgical treatments of chronic subdural hematoma and outcome in 172 patients: is membranectomy necessary? Surg Neurol 2004;61(6):523-527, discussion 527-528

16 Lee JK, Choi JH, Kim CH, Lee HK, Moon JG. Chronic subdural hematomas : a comparative study of three types of operative procedures. J Korean Neurosurg Soc 2009;46(3):210-214

17 Miranda LB, Braxton E, Hobbs J, Quigley MR. Chronic subdural hematoma in the elderly: not a benign disease. J Neurosurg 2011; 114(1):72-76

18 Rughani AI, Lin C, Dumont TM, Penar PL, Horgan MA, Tranmer BI. A case-comparison study of the subdural evacuating port system in treating chronic subdural hematomas. J Neurosurg 2010;113(3): 609-614

19 Sambasivan M. An overview of chronic subdural hematoma: experience with 2300 cases. Surg Neurol 1997;47(5): 418-422

20 Tanikawa M, Mase M, Yamada K, et al. Surgical treatment of chronic subdural hematoma based on intrahematomal membrane structure on MRI. Acta Neurochir (Wien) 2001;143(6): 613-618, discussion 618-619

21 White M, Mathieson CS, Campbell E, Lindsay KW, Murray L. Treatment of chronic subdural haematomas - a retrospective comparison of minicraniectomy versus burrhole drainage. $\mathrm{Br} \mathrm{J}$ Neurosurg 2010;24(3):257-260

22 Williams GR, Baskaya MK, Menendez J, Polin R, Willis B, Nanda A. Burr-hole versus twist-drill drainage for the evacuation of chronic subdural haematoma: a comparison of clinical results. J Clin Neurosci 2001;8(6):551-554

23 Smely C, Madlinger A, Scheremet R. Chronic subdural haematoma -a comparison of two different treatment modalities. Acta Neurochir (Wien) 1997;139(9):818-825, discussion 825-826

24 Muzii VF, Bistazzoni S, Zalaffi A, Carangelo B, Mariottini A, Palma L. Chronic subdural hematoma: comparison of two surgical techniques. Preliminary results of a prospective randomized study. J Neurosurg Sci 2005;49(2):41-46, discussion 46-47

25 Baechli H, Nordmann A, Bucher HC, Gratzl O. Demographics and prevalent risk factors of chronic subdural haematoma: results of a large single-center cohort study. Neurosurg Rev 2004;27(4): 263-266

26 Han HJ, Park CW, Kim EY, Yoo CJ, Kim YB, Kim WK. One vs. Two Burr Hole Craniostomy in Surgical Treatment of Chronic Subdural Hematoma. J Korean Neurosurg Soc 2009;46(2):87-92

27 Kansal R, Nadkarni T, Goel A. Single versus double burr hole drainage of chronic subdural hematomas. A study of 267 cases. J Clin Neurosci 2010;17(4):428-429

28 Taussky P, Fandino J, Landolt H. Number of burr holes as independent predictor of postoperative recurrence in chronic subdural haematoma. Br J Neurosurg 2008;22(2):279-282 
29 Kuroki T, Katsume M, Harada N, Yamazaki T, Aoki K, Takasu N. Strict closed-system drainage for treating chronic subdural haematoma. Acta Neurochir (Wien) 2001;143(10): 1041-1044

30 Oishi M, Toyama M, Tamatani S, Kitazawa T, Saito M. Clinical factors of recurrent chronic subdural hematoma. Neurol Med Chir (Tokyo) 2001;41(8):382-386

31 Suzuki K, Sugita K, Akai T, Takahata T, Sonobe M, Takahashi S. Treatment of chronic subdural hematoma by closed-system drainage without irrigation. Surg Neurol 1998;50(3):231-234

32 Torihashi K, Sadamasa N, Yoshida K, Narumi O, Chin M, Yamagata $\mathrm{S}$. Independent predictors for recurrence of chronic subdural hematoma: a review of 343 consecutive surgical cases. Neurosurgery 2008;63(6):1125-1129, discussion 1129

33 Tsutsumi K, Maeda K, Iijima A, Usui M, Okada Y, Kirino T. The relationship of preoperative magnetic resonance imaging findings and closed system drainage in the recurrence of chronic subdural hematoma. J Neurosurg 1997;87(6):870-875

34 Wakai S, Hashimoto K, Watanabe N, Inoh S, Ochiai C, Nagai M. Efficacy of closed-system drainage in treating chronic subdural hematoma: a prospective comparative study. Neurosurgery 1990; 26(5):771-773

35 Erol FS, Topsakal C, Faik Ozveren M, Kaplan M, Tiftikci MT. Irrigation vs. closed drainage in the treatment of chronic subdural hematoma. J Clin Neurosci 2005;12(3):261-263

36 Javadi A, Amirjamshidi A, Aran S, Hosseini SH. A randomized controlled trial comparing the outcome of burr-hole irrigation with and without drainage in the treatment of chronic subdural hematoma: a preliminary report. World Neurosurg 2011;75(56):731-736, discussion 620-623

37 Kiymaz N, Yilmaz N, Mumcu C. Controversies in chronic subdural hematoma: continuous drainage versus one-time drainage. Med Sci Monit 2007;13(5):CR240-CR243

38 Lind CR, Lind CJ, Mee EW. Reduction in the number of repeated operations for the treatment of subacute and chronic subdural hematomas by placement of subdural drains. J Neurosurg 2003; 99(1):44-46

39 Santarius T, Kirkpatrick PJ, Ganesan D, et al. Use of drains versus no drains after burr-hole evacuation of chronic subdural haematoma: a randomised controlled trial. Lancet 2009;374(9695):1067-1073

$40 \mathrm{Yu}$ GJ, Han CZ, Zhang M, Zhuang HT, Jiang YG. Prolonged drainage reduces the recurrence of chronic subdural hematoma. $\mathrm{Br} \mathrm{J}$ Neurosurg 2009;23(6):606-611
41 Yamamoto H, Hirashima Y, Hamada H, Hayashi N, Origasa H, Endo $\mathrm{S}$. Independent predictors of recurrence of chronic subdural hematoma: results of multivariate analysis performed using a logistic regression model. J Neurosurg 2003;98(6):1217-1221

42 Nakaguchi H, Tanishima T, Yoshimasu N. Relationship between drainage catheter location and postoperative recurrence of chronic subdural hematoma after burr-hole irrigation and closedsystem drainage. J Neurosurg 2000;93(5):791-795

43 Escosa Baé M, Wessling H, Salca HC, de Las Heras Echeverría P. Use of twist-drill craniostomy with drain in evacuation of chronic subdural hematomas: independent predictors of recurrence. Acta Neurochir (Wien) 2011;153(5):1097-1103

44 Abouzari M, Rashidi A, Rezaii J, et al. The role of postoperative patient posture in the recurrence of traumatic chronic subdural hematoma after burr-hole surgery. Neurosurgery 2007;61(4): 794-797, discussion 797

45 Ishfaq A, Ahmed I, Bhatti SH. Effect of head positioning on outcome after burr hole craniostomy for chronic subdural haematoma. J Coll Physicians Surg Pak 2009;19(8):492-495

46 Nakajima H, Yasui T, Nishikawa M, Kishi H, Kan M. The role of postoperative patient posture in the recurrence of chronic subdural hematoma: a prospective randomized trial. Surg Neurol 2002;58(6):385-387, discussion 387

47 Kurabe S, Ozawa T, Watanabe T, Aiba T. Efficacy and safety of postoperative early mobilization for chronic subdural hematoma in elderly patients. Acta Neurochir (Wien) 2010;152(7): 1171-1174

48 Miele VJ, Sadrolhefazi A, Bailes JE. Influence of head position on the effectiveness of twist drill craniostomy for chronic subdural hematoma. Surg Neurol 2005;63(5):420-423, discussion 423

49 Markwalder TM. Chronic subdural hematomas: a review. J Neurosurg 1981;54(5):637-645

50 Putnam T, Cushing H. Chronic subdural hematoma: its pathology, its relations to pachymeningitis hemorrhagica and its surgical treatment. Arch Surg 1925;11:329-393

51 Sato S, Suzuki J. Ultrastructural observations of the capsule of chronic subdural hematoma in various clinical stages. J Neurosurg 1975;43(5):569-578

52 Zakaraia AM, Adnan JS, Haspani MS, Naing NN, Abdullah JM. Outcome of 2 different types of operative techniques practiced for chronic subdural hematoma in Malaysia: an analysis. Surg Neurol 69:608-615; discussion 616, 2008. 